\title{
CONSTRUÇÃO DO ESTADO, ESFERA POLÍTICAE PROFISSIONALIZAÇÃO DO JORNALISMO NO BRASIL
}

\author{
Fernanda Rios Petrarca
}

\begin{abstract}
RESUMO
Este artigo analisa a relação entre o processo de construção do Estado e o projeto proposto para a organização dos universos profissionais no Brasil, tomando como referência empirica o caso do jornalismo e sua respectiva profissionalização, e levando em consideração a relação entre o surgimento dos critérios formais de entrada na atividade, a criação de entidades de representação da categoria e o estabelecimento das instituições de ensino com os usos sociais deste processo e com as trajetórias dos agentes envolvidos. Um dos objetivos principais deste texto consiste em fornecer elementos, com base em determinadas concepções teóricas e metodológicas, para pensar o processo de organização e institucionalização das profissões no Brasil e sua relação com a esfera política, de modo geral. No contexto brasileiro, tem se observado que a dinâmica de construção de uma esfera política e profissional ocorre simultaneamente e com uma forte interferência entre elas. Portanto, a partir da experiência do jornalismo, demonstra-se que o reconhecimento profissional se tornou um recurso para a atuação na política brasileira. PALAVRAS-CHAVE: Estado; profissão; jornalismo; esfera política.
\end{abstract}

\section{INTRODUÇÃO}

Este artigo apresenta uma análise da relação entre a construção do Estado Nação e o projeto proposto para a organização dos universos profissionais no Brasil, com ênfase para o caso específico do jornalismo e de sua respectiva profissionalização. Uma das preocupações centrais, que orientou este texto, está relacionada às possibilidades de ampliação e intensificação das discussões, já consagradas na Sociologia, do papel e do peso das profissões nos processos de construção do Estado nacional e da importância da esfera política na constituição de um projeto profissional. Parte-se do princípio de que os processos de profissionalização pelos quais passam as atividades ocupacionais não representam apenas uma forma de controle sobre a atividade e as reservas de espaços no mercado de trabalho, mas constituem, também, os confrontos pela definição dos recursos legítimos para o ingresso e exercício profissional (BOLTANSKI, 1982; BOURDIEU, 1984; BOIEGOL \& DEZALAY, 1997; DEZALAY \& GARTH, 2002). Nesses confrontos, a esfera política e os recursos oriundos dos vínculos e investimentos em tal esfera têm se mostrado, como destaca a literatura nacional, fundamentais para a definição de um espaço de atuação profissional.
O estudo da relação entre Estado, esfera política e projeto profissional constituiu-se nas Ciências Sociais como objeto legítimo de um conjunto de pesquisas, que suscitou divergentes interrogações. A literatura referente à chamada Sociologia das Profissões tem destacado que o poder profissional está diretamente associado a uma menor influência e intervenção do Estado, e do campo político de modo geral, no controle e na organização das profissões. Essa escola, apesar de internamente diferenciada no que diz respeito às concepções sobre os processos de profissionalização, foi marcada pela análise do sistema de credenciamento social e dos critérios fundamentais de admissão numa profissão. Para os funcionalistas, que marcaram uma longa tradição na análise dessa temática, a profissionalização e a exigência de critérios legais tornavam-se fundamentais para garantir a qualidade dos serviços prestados, uma vez que os clientes não dispunham de competências para apreciar tais serviços. Nessa perspectiva, o Estado tinha meramente o papel de conceder o monopólio legal às profissões reconhecendo a superioridade técnica das atividades profissionais (PARSONS, 1977).

Entretanto, é com base nas críticas à escola funcionalista que as gerações seguintes relacionaram o processo de profissionalização à formação de um mercado fechado, a um instrumento de 
poder e à base de um monopólio. Por um lado, alguns estudiosos, voltados à Sociologia interacionista, relacionaram a preservação do controle profissional e a organização para manter a autonomia aos processos de interação social (HUGHES, 1981). Por outro, a crítica ao modelo internalista da análise das profissões, realizada pelo funcionalismo, cedeu lugar às novas teorias sobre as profissões, que se desenvolveram no curso dos anos 1970 e 1980 (DUBAR \& TRIPIER, 1998). Esse momento é marcado pelo contexto social e ideológico da época, no qual havia um acentuado antiprofissionalismo e uma dura crítica às profissões como um sistema injusto e desigual (RODRIGUES, 2002). Dentre os autores a ganhar proeminência, nesse contexto, estão Magali Larson e Eliott Freidson. Esses autores, de maneiras diferentes, relacionaram o processo de profissionalização a um conjunto de estratégias coletivas para estabelecer o monopólio sobre um mercado específico de serviços, com a ajuda do Estado. Nesse sentido, o Estado concede à profissão a autoridade legal para selecionar, recrutar, examinar, licenciar, reavaliar desempenhos e estabelecer os limites formais de sua jurisdição. Contudo, a distância em relação à política governamental é essencial para demarcar a independência das profissões com relação ao universo político. Ao construir uma política própria, as profissões protegem-se dos interesses específicos do mundo da política. Portanto, o domínio da perícia (expertise) e a demarcação de fronteiras no mundo do trabalho são as características principais da profissionalização.

Tais autores permitiram demonstrar que, em determinados contextos sociais, políticos e econômicos, a história das profissões tem sido marcada pela progressiva autonomia concedida a determinados grupos profissionais, pelo Estado, para realizar a função de reprodução e controle do mercado (BARBOSA, 1993; FREIDSON, 1998; 2001). Nessa linha, as profissões não estão separadas do processo político de construção do Estado moderno que concede menor ou maior autonomia aos grupos profissionais na definição dos critérios de acesso aos postos. Destacou-se, como objeto de análise, o papel do Estado como intermediário desse processo, considerando seu maior ou menor poder de influência, seu grau de centralização, o desenvolvimento do Estado-providência e o tipo de intervenção sobre os sistemas de ensino e formação (RODRIGUES, 2002).
Enquanto, nas abordagens funcionalistas, o Estado responde quase que de maneira passiva na aprovação das competências específicas das profissões e nos direitos das associações profissionais, nas análises posteriores, o poder profissional aparece associado ao poder do Estado, uma vez que as instituições do profissionalismo necessitam do Estado para manterem-se e estabelecerem espaços reservados de atuação (FREIDSON, 1996). Contudo, um dos limites desse modelo centrado no mercado é o de não considerar os processos de institucionalização das profissões como uma maneira de ter acesso aos recursos do Estado e de fazer das carreiras profissionais uma forma de promover-se no Estado e de conquistar funções políticas e profissionais.

Em situações como a brasileira, um conjunto vasto de trabalhos tem demonstrado que a regulamentação das profissões e a exigência da formação acadêmica voltaram-se não só para uma reserva de espaços, mas constituíram-se como recursos fundamentais para atuar na esfera política. Nesse sentido, o processo de profissionalização das profissões envolveu tanto o Estado, que ofereceu oportunidades para que as elites profissionais usassem seu conhecimento para investir na construção política do país, como os segmentos sociais de elite, que se organizaram para influenciar o processo político por meio do conhecimento formal, obtido em universidades. Estudos sobre o Direito (BONELLI, 1999; DEZALAY \& GARTH, 2002) revelam uma relação dinâmica entre Estado e direito, em que os advogados brasileiros, por meio das associações profissionais, exploraram um diversificado conjunto de possibilidades para influenciar o Estado, e não exclusivamente controlar o mercado. Assim, o Estado atuou como promotor da cooptação profissional, apadrinhando, inclusive com nomeação para postos públicos, os membros dessas organizações. Processo semelhante aconteceu com os economistas (LOUREIRO, 1997), em que os conselhos técnicos e outros, criados pelo Estado, contribuíram para a formação do campo dos economistas no Brasil, além de consolidá-los como um novo segmento da elite dirigente, capaz ocupar os postos oferecidos pelo Estado, por meio do conhecimento técnico. Por conseguinte, as competências profissionais pouco eram avaliadas pelas capacidades técnicas, e uma das características principais era a inserção dos profissionais em outras atividades, para elevar seu prestígio social e profissional. 
Assim, o processo de formação das profissões e a imposição dos critérios legais constituíram-se como uma forma de ter acesso ao Estado e, de modo geral, à esfera política que está na base de todo esse processo. A regulamentação e a exigência de critérios oficiais, como o diploma, constituíram-se como recursos vitais para agir em outras esferas sociais e, conseqüentemente, colocar a profissão a serviço de causas sociais diversas. Em função disso, as instituições de defesa da categoria exerceram tanto o papel de controle do exercício profissional e sua institucionalização como constituíram-se como instâncias de acumulação de recursos sociais fundamentais para permitir um investimento na política estatal. Portanto, profissionalização e intervenção política não são atividades antagônicas, muito pelo contrário, as instituições acadêmicas e as entidades de defesa dos profissionais que mais se destacaram foram justamente aquelas que também exigiram de seus membros, ao mesmo tempo, profissionalização e inserção política. Isso implica afirmar que o poder profissional, nessas condições, está associado ao poder de intervenção na esfera política (PÉCAUT, 1990; BONELLI, 1999; COELHO, 1999; BARICKMAN \& LOVE, 2006).

Desse modo, não há como compreender o fenômeno profissional brasileiro considerando as profissões como submetidas apenas às regras do mercado ou do Estado, como já assinalaram autores como Coelho (1999) e Bonelli (1999). Para compreender os processos de profissionalização, em situações como a brasileira, há que se considerar o processo de imbricação entre as esferas política e profissional e entre os recursos a elas associados. Diante de tais considerações, este artigo centra-se no exame do processo de profissionalização do jornalismo no Brasil, levando em consideração a relação entre o surgimento dos critérios formais de entrada na atividade, a criação de entidades de representação da categoria e o estabelecimento das instituições de ensino com os usos sociais desse processo e com as trajetórias dos agentes envolvidos. Portanto, sem desprezar a noção de profissão e de profissionalização (FREIDSON, 1984), trata-se de apreender os recursos sociais e os princípios de legitimação que estão na base dos processos de profissionalização (BOLTANSKI, 1982; BOURDIEU, 1984; BOIEGOL \& DEZALAY, 1997; DEZALAY \& GARTH, 2002).

\section{A PROFISSIONALIZAÇÃO DO JORNALIS- MO E SUA RELAÇÃO COM O ESTADO EA ESFERA POLÍTICA}

A primeira legislação da profissão foi criada em 30 de novembro de 1938, pelo governo ditatorial de Getúlio Vargas, juntamente com as assessorias dos sindicatos de jornalistas de São Paulo e do Rio de Janeiro. Esse Decreto buscava regulamentar a duração e as condições de trabalho nas empresas jornalísticas, definindo as principais funções ocupadas pelos jornalistas: Redator-Chefe, Secretário, Subsecretário, Chefe e Subchefe de Revisão, Chefe de Oficina, de Ilustração e de Portaria (MARANHÃO FILHO, 1995). Um dos objetivos e uma das principais intenções era o de registrar e cadastrar aqueles que tinham vínculos com a imprensa, pois se considerava jornalista todo aquele "homem de imprensa" devidamente registrado no Ministério do Trabalho; condição fundamental para sua admissão no jornal. Dessa forma, o Estado passava a ter o controle sobre aqueles que desempenhavam atividades em jornais.

O momento de criação desse Decreto ocorreu em um período de intensas crises do governo com a imprensa. O Estado Novo, instituído por Getúlio Vargas, estabeleceu a censura no país e criou órgãos como o Departamento de Imprensa e Propaganda (DIP), cujo objetivo era controlar a imprensa e o rádio. A primeira fase deu-se pelo fechamento de muitos jornais e revistas que tinham vínculos políticos partidários, mas caracterizouse também pelo investimento do governo em sua propaganda, criando revistas culturais e jornais em diversos estados. Dentre essas revistas e jornais, pode-se citar o jornal $A$ Manhã e a revista Cultura Política, que contavam com a participação de muitos pensadores e escritores brasileiros. Como todos os meios de comunicação social, o setor de rádio foi um dos veículos que mais obteve investimento do governo e traduziu-se, principalmente, no programa Hora do Brasil, cujo objetivo era o de transmitir para todas as estações de rádio os principais acontecimentos da vida do país e incentivar a cultura nacional.

A regulamentação da profissão de jornalista e o processo de estabelecimento dos primeiros critérios jurídico-institucionais estão relacionados tanto ao projeto para organizar a profissão proposto pelos jornalistas e às convicções políticas de que os mesmos estavam imbuídos, como à 
proposta do governo para a organização de um conjunto de profissões. Nesse processo de regulamentação dos ofícios, o Estado e seu aparato burocrático tornaram-se fundamentais para a formação dos grupos profissionais, proporcionando espaços em que poderiam atuar em nome de suas especialidades. Por meio de órgãos como o DIP e das revistas que propagandeavam o regime, o Estado oferecia aos jornalistas a possibilidade de intervir na burocracia pública e fazer desse espaço um trunfo imprescindível para o êxito do jornalismo. Do mesmo modo, as profissões tornaram-se essenciais para formação do Estado brasileiro, constituindo-se como um conjunto de saberes especializados apresentados como fundamentais para traçar os caminhos da nação. Os jornalistas, assim como um conjunto de outros profissionais, passaram a reivindicar uma participação na montagem do projeto político do Estado nacional.

Uma grande parte dos jornalistas, nesse contexto, participava ativamente das lutas políticas, não só exaltando o caráter brasileiro e a nação, mas também atuando diretamente na política, filiando-se aos partidos políticos locais e ocupando cargos na burocracia pública. Como exemplo da articulação bem-sucedida entre jornalismo, participação nas lutas políticas e inserção na burocracia pública, pode-se citar o caso de Cassiano Ricardo e Lourival Fontes, que, além de participarem ativamente da política do país, tinham uma forte atuação na imprensa, publicando em jornais e revistas, e dentro do próprio Estado. Cassiano Ricardo, engajado na "construção da nação", publicou várias obras sobre o Brasil, dentre as quais se destaca o ensaio "O Brasil no Original". Seu engajamento político não se limitou a uma busca pela nação brasileira, mas manifestou-se na filiação a partidos políticos locais, atuando no Partido Republicano Paulista (PRP), e em sua inserção na burocracia pública, dirigindo o Departamento Estadual de Imprensa e Propaganda de São Paulo, o Departamento Cultural da Rádio Nacional e o jornal $A$ Manhã, durante o Estado Novo. Formado em Direito, atuou em diversas frentes. Foi colaborador em vários jornais e revistas de São Paulo, participou ativamente da reforma literária iniciada na Semana da Arte Moderna, em 1922; fundou também o movimento político contra o Integralismo, juntamente a Menoti del Picchia. Nesse momento, dirigiu o jornal $O$ Anhanguera, na tentativa de recuperar a "democracia social brasileira". Pertenceu à Academia Paulista de Letras, ingressou na Academia Brasileira de Letras durante o Estado Novo e pertenceu ao Conselho Federal da Cultura.

De maneira semelhante, Lourival Fontes também atuou em diversas áreas, em prol do nacionalismo. Colaborou em diversos jornais de Sergipe e da Bahia; participou da Aliança Liberal que tinha à frente Getúlio Vargas. Fundou e dirigiu revistas e jornais, foi diretor da Secretaria do Gabinete da Prefeitura do Distrito Federal e dirigiu o Departamento de Imprensa e Propaganda (DIP) durante o Estado Novo.

Essa articulação entre a participação nas lutas políticas e o jornalismo, manifestada não só pela exaltação da nacionalidade, mas também pela inserção em partidos políticos, pode ser percebida também entre aqueles que representavam as principais entidades que visavam reunir jornalistas naquele período e que defendiam o estabelecimento de critérios formais para exercer a profissão. A inserção simultânea em entidades de representação, partidos políticos, burocracia pública e jornais, caracterizou as lideranças de entidades nacionais como a Associação Brasileira de Imprensa (ABI), associações de imprensa locais e sindicatos profissionais.

Assim, muitos jornalistas conseguiram inserir-se nos espaços privilegiados do serviço público, e o Estado constituiu-se em um trunfo imprescindível para o êxito do jornalismo. Nesse contexto, aumentava a capacidade de intervir, em nome da profissão, na política; e o Estado tornava-se o promotor dos serviços, cooptando os profissionais. Ao mesmo tempo em que o Estado Novo oferecia a alguns jornalistas a possibilidade de atuar na burocracia pública por meio de órgãos como o DIP e das revistas que propagandeavam o regime, os jornalistas, de modo geral, também reivindicavam ter participação na montagem de seu projeto político.

Nas décadas de 1920 e 1930, o jornalismo, assim como a literatura e algumas instituições, como as de ensino superior, foi colocado a serviço da recuperação da nacionalidade e tornou-se instrumento de transformação social e política. O projeto corporativo, que visava organizar as profissões, defendido pelos jornalistas e por outros atores que desenvolviam atividades específicas escritores, médicos e advogados -, era inseparável da vontade de colaborar para organizar a cultura e 
a política. Aqueles que se dedicavam à arte, à literatura, ao cinema, à Medicina, ao jornalismo e a diversas outras áreas, associavam suas atividades à preocupação de colocarem-se a serviço da construção política do país. Desse modo, a "profissão" tornava-se um meio, um recurso, para atuar na organização política da nação e inserir-se na política estatal. Isso foi muito diferente do que aconteceu em países como os Estados Unidos, onde os jornalistas, para reivindicarem uma condição de profissão, precisaram definir essa atividade como um grupo específico com um saberfazer próprio e constituída por um "corpo profissional autônomo" que atuava distante da política e voltado essencialmente para um mercado econômico (NEVEU, 2001).

Desse modo, tanto o nacionalismo, veiculado por grande parte dos jornalistas, sobretudo aqueles inseridos na burocracia pública e vinculados a instâncias de representação da categoria, como o projeto que tais jornalistas defendiam para organizar as profissões, aparecem como uma maneira de obter o reconhecimento do Estado e, ao mesmo tempo, possibilitar o acesso a ele. "Nacionalismo", "caráter nacional", "realidade brasileira" e "organização profissional" aparecem como noções imbricadas, uma vez que era o "Estado Nacional", na visão desses jornalistas, que deveria criar as condições para o sentimento nacional e para a organização corporativa. O esquema corporativo enunciado e proclamado por esses atores sociais, como a regulamentação das profissões e a criação das leis trabalhistas, não está separado de suas convicções políticas e pretensões em atuar em prol da nação. O pertencimento a uma categoria profissional e a atuação política aparecem como indistintos, uma vez que um dos motivos que contribuiu para que um conjunto diverso de atores inserisse-se na política, nesse momento, foi justamente o sentimento de pertencer a uma categoria profissional (PÉCAUT, 1990).

A profissão tornava-se um instrumento importante de intervenção na política do país. No jornalismo, as entidades voltadas à representação da categoria, nesse contexto, passaram a reivindicar o papel dos jornalistas na construção da política brasileira. Dentre essas entidades, estão a Associação Brasileira de Imprensa, fundada em 1908, a Associação Paulista de Imprensa, fundada em 1933, o Sindicato dos Jornalistas do Rio de Janeiro, em 1935 e o Sindicato dos Jornalistas de São Paulo, fundado em 1937. O questionamento da missão política do jornalista passava a ser objeto de debate de um conjunto de congressos e seminários, promovidos por essas associações recémcriadas. Esses congressos tinham como objetivo intensificar a força política da categoria. Isso fica ainda mais claro no Primeiro Congresso de Jornalistas de São Paulo, realizado em 1933, no discurso de abertura: "Somos o espírito que anima a matéria. Do valor prático e ideológico do nosso pensamento é que se deduz a altura do nível em que se acha a nossa civilização. Somos uma força; somos uma alavanca; somos um impulso para a frente; mas fomos, até hoje, uma força destituída de finalidade, como uma flecha sem alvo, uma alavanca sem fulcro, um beijo sem boca, um impulso sem sentido, um verbo sem articulação" (HIME, 2005a, p. 3).

É verdade que nem todos os jornalistas da época partilhavam das mesmas concepções de jornalismo e política, mas, em sua grande maioria, mostravam-se de acordo com o fortalecimento das funções do Estado. Apesar de já existir uma identidade nacional e um povo genuinamente brasileiro, isso não bastava para consolidá-lo, era ainda fundamental traçar uma cultura brasileira e assegurar sua unidade. Os grupos profissionais, e, dentre eles o do jornalismo, reivindicaram uma condição de elite, uma vez que cabia e eles a organização da nação. Essa geração herdou, daquela que a antecedeu, a idéia de que sua missão era, antes de tudo, política, e que era preciso colocarse a serviço do Estado Nacional. Esse sentido de missão mostra o processo de conversão dos membros de profissões, nesse caso, os jornalistas, em agentes políticos. Contudo, essa missão não se resumiu à defesa da nação, manifestou-se também na inserção em partidos políticos e na burocracia pública.

O projeto corporativista, instaurado pelo Estado Novo, tinha como objetivo "organizar" tanto a sociedade, de um modo geral, como um conjunto de atores que desempenhavam atividades profissionais (especialmente, médicos, escritores, advogados e jornalistas). Muitos desses atores desempenhavam várias dessas atividades ao mesmo tempo. Esse projeto incluía a regulamentação das profissões, as leis trabalhistas, a legislação sindical e outros que se apoiavam na atribuição de direitos moldados em função da filiação profissional. As profissões foram reconhecidas e receberam um estatuto oficial, o que possibilitou identidades e direitos específicos. Nesse período, além 
da regulamentação da profissão de jornalista, foram fundadas algumas organizações como a Ordem dos Advogados do Brasil, criada em 1930, a Academia de Medicina, fundada em 1931, o Conselho de Engenharia e Arquitetura, em 1933, e o Sindicato dos Escritores. O objetivo da regulamentação profissional não consistia em questionar as atividades desempenhadas pelos seus representantes, mas permitir que as elites de determinadas profissões pudessem determinar as condições de ingresso e intervir na política, em nome de uma "ética profissional" (PÉCAUT, 1990).

O Decreto de 1938 não foi o último, nem o único a regulamentar a "profissão" de jornalista. Posteriormente a ele, instaurou-se o Decreto de 1943 e 1944. Com a consolidação das leis do trabalho em 1943, repetem-se os artigos do Decreto anterior, não alterando a distinção feita entre profissionais de imprensa. Esse Decreto adicionava a criação dos cursos de jornalismo no ensino superior. O Decreto de 1944 acrescentou a remuneração mínima daqueles que trabalhavam em atividades jornalísticas e enquadrava como jornalistas também os redatores existentes na radiodifusão e na redação publicitária. Nesse Decreto, todos os que trabalhassem em imprensa teriam de titularse como jornalista, desde o diretor ao arquivista. Acrescentaram-se ainda o fotógrafo como função auxiliar de redação ao lado do revisor, ilustrador ou desenhista e arquivista. O Decreto de 1938 apenas diferenciava o jornalista do locutor e do fotógrafo, mas não o classificava dentro da hierarquia. O Decreto de 1944, além de enquadrar radialistas e publicitários como jornalistas, classificava o fotógrafo como auxiliar dos jornalistas.

Outros decretos somaram-se a esses, como os de 1961, 1962, 1963 e 1969. O Decreto de 1961 colocava a necessidade de cumprir o Decreto de 1938. Segundo Maranhão Filho (1995), a falta de regulamentação do Decreto de 1938 prejudicava o funcionamento das escolas de jornalismo já existentes e que, por não se constituírem como um curso obrigatório para o ingresso na profissão, não despertaram o interesse da classe. Já o Decreto de 1962 modificava a definição de jornalista acrescentando-lhe o fotógrafo já como jornalista. O Decreto de 1963 manteve a mesma conceituação de jornalista profissional, omitindo o locutor e acrescentando o estagiário de jornalismo como não diplomado, permanecendo a criação de cursos de jornalismo em nível universitário. Uma das principais modificações foi estabelecida pelo Decreto de 1969, que instituía a obrigatoriedade de diploma, em jornalismo, para exercer a profissão no país, acrescentando a necessidade de remuneração mínima. Tal Decreto amplificou aquilo que compreende a atividade jornalística, incluindo outras tarefas designadas ao jornalismo, como o ensino de técnicas jornalísticas. Uma de suas principais funções foi a de valorizar os cursos de jornalismo e impedir o exercício da profissão a pessoas que não eram formadas em cursos de nível superior.

\section{AS ENTIDADES DE REPRESENTAÇÃO DA CATEGORIA: RECURSOS POLÍTICOS E CONSAGRAÇÃO SOCIAL}

O papel desempenhado pelas instituições de representação dos jornalistas está relacionado ao processo mais amplo de institucionalização das profissões no Brasil e aparece associado tanto à função que as profissões atribuíram-se na elaboração da imagem da nação, como à tradição estatal que conferiu aos profissionais e às entidades de defesa das categorias a capacidade de contribuírem para a construção da nação. As entidades de representação dos jornalistas tiveram seu estímulo durante o Estado Novo, momento em que o processo de regulamentação da atividade jornalística iniciava-se, e as instituições passaram a ser consideradas espaços importantes para o estabelecimento de vínculos com a política estatal. Ampliava-se o número de sindicatos e de entidades voltadas aos jornalistas, no país, com o objetivo de enquadrar a categoria. O estímulo à organização profissional levou a uma diversificação de entidades e a uma forte concorrência entre elas, uma vez que tais entidades permitiam que aqueles que a elas dedicavam-se acumulassem uma série de recursos que possibilitavam uma aproximação com o Estado e com a esfera da política, de modo geral. Assim, as entidades exerciam, ao mesmo tempo, a função de recrutamento de jornalistas, definindo as características sociais daqueles que nela deveriam ingressar, e a de consagração social de seus membros, contribuindo para o acesso a outras esferas, ampliando as possibilidades de atuação profissional.

Na década de 1930, já existiam no Rio de Janeiro três entidades, além da ABI, agregando jornalistas: Clube de Imprensa, Associação da Imprensa Brasileira e o Sindicato dos Jornalistas do Município do Rio de Janeiro. Em São Paulo, na década de 1940, já existiam pelo menos cinco 
entidades representativas dos jornalistas: a Associação Paulista de Imprensa, a Associação dos Profissionais de Imprensa de São Paulo, a Associação dos Jornalistas Católicos, o Sindicato dos Jornalistas de São Paulo e a Associação dos Cronistas de São Paulo. A diversidade de instituições contribuiu para uma forte concorrência entre seus representantes, que precisaram investir, cada vez mais, na mobilização de recursos amplos e variados, que decorriam da inserção em várias esferas, sobretudo na esfera política e cultural, com destaque para entidades como a Academia Brasileira de Letras e o Instituto Histórico e Geográfico Brasileiro.

Alguns casos podem ser mencionados para ilustrar a inserção dos dirigentes de entidades profissionais em várias esferas sociais e o acúmulo de recursos diversificados. A começar pelo Redator-Chefe do jornal Correio da Manhã, membro da Associação Brasileira de Imprensa, Pedro Costa Rego, que, nesse período, já havia sido Secretário da Agricultura, Deputado Federal e Senador. Além de ter sido o primeiro professor a ministrar cadeiras de jornalismo brasileiro na recém-criada Universidade do Distrito Federal, atuou também como escritor e literato, compondo romances e obras críticas. Juntamente a Pedro Costa Rego, está Barbosa Lima Sobrinho, Presidente da Associação Brasileira de Imprensa por três gestões (1926-1927; 1930-1932 e 1978-2000) e Herbert Moses, Presidente da ABI de 1931 até 1964. Barbosa Lima Sobrinho, além de jornalista, acumulava as funções de advogado, ensaísta, historiador, político e professor. Foi Deputado Federal, Governador de Pernambuco e Procurador do Rio de Janeiro, compondo assim a elite cultural e política do país. Iniciou no jornalismo como colaborador logo após ter concluído o curso de Direito, tornando-se noticiarista e redator político. Seu ingresso na $\mathrm{ABI}$, e sua atuação como dirigente da entidade, ocorreu antes de sua entrada na política, e contribuiu para aproximá-lo dessa esfera, visto que a entidade era, nesse período, permeada por diversos políticos. Já Herbert Moses, além de jornalista e diretor do jornal $O$ Globo, era também advogado e diretor da empresa Souza Cruz, no momento em que se tornou Presidente da ABI. Diferente dos casos anteriores, em que foi a condição de Presidente da entidade que permitiu o acesso a outras funções, no caso de Moses, foram seus laços externos que contribuíram para fortalecer a relação da entidade com as empresas e com o universo da política governamental, sobretudo com o Ministério das Relações Exteriores.

Ainda é possível citar o jornalista, ilustrador e chargista Lívio Abramo, um dos fundadores do Sindicato dos Jornalistas Profissionais de São Paulo. Lívio Abramo atuou ativamente no Partido Comunista Brasileiro, mas devido às suas posturas "trotskistas", foi expulso, vinculando-se ao Partido Socialista Brasileiro. Abramo também ficou conhecido por suas gravuras e desenhos que, nesse período, passaram a abordar as temáticas sociais; a rotina dos operários e o funcionamento das fábricas. Contribuiu, ao mesmo tempo, ao Sindicato dos Artistas Plásticos de São Paulo. Outro jornalista a destacar-se foi Guilherme de Almeida, Presidente da Associação Paulista de Imprensa, em 1937. Formado em Direito, atuou como jornalista de vários jornais de São Paulo, tendo sido membro também da Academia Paulista de Letras, da Academia Brasileira de Letras e do Instituto Histórico e Geográfico de São Paulo. Guilherme escrevia poemas e obras críticas, e atuou politicamente engajando-se na Revolução Constitucionalista de 1932. Além desses nomes, destaca-se o jornalista Edgard Leuenroth, um dos primeiros diretores do Sindicato dos Profissionais de Imprensa do Rio de Janeiro, depois denominado Sindicato dos Jornalistas do Rio de Janeiro. Atuou juntamente à fundação do Partido Comunista Brasileiro, na Federação Operária e diversas entidades anarquistas, assim como na Associação Paulista de Imprensa e no Sindicato dos Gráficos. Esse jornalista organizou e editou vários jornais oficiais de movimentos políticos, estruturando também o Primeiro Congresso de Jornalistas (1918) e o Primeiro Congresso Paulista de Imprensa (1933).

Os jornalistas representantes das associações profissionais e de defesa do jornalismo, nesse período, ao mesmo tempo em que desenvolviam todo um trabalho voltado para essa área (promoção de congressos, estimulação da criação de escolas de jornalismo e leis que regulamentassem o exercício dessa atividade) atuavam politicamente contra regimes autoritários, promovendo a liberdade de imprensa e de expressão e inserindo-se em partidos políticos locais. Suas participações não se restringiam a um único universo, mas a vários espaços sociais, como o da arte, da cultura e da política, desempenhando, por conseguinte, uma diversidade de papéis. Portanto, além desses pro- 
fissionais contarem com suas associações profissionais, nesse período, como a Associação Brasileira de Imprensa, eles dispunham de outras entidades de cunho literário e cultural para ampliar seu prestígio e capital social, como a Academia Brasileira de Letras e o Instituto Histórico e Geográfico. A multiplicidade de instâncias de consagração, que são ao mesmo tempo mais complementares do que concorrentes, permitia aos profissionais atuarem em diversos espaços simultaneamente e buscarem prestígio também fora das associações específicas. Além disso, por meio da inserção em diversos espaços e do exercício de várias funções, esses jornalistas acreditavam estar contribuindo para fundamentar uma cultura nacional e organizar o Estado brasileiro.

Entretanto, não foram somente os jornalistas, membros das entidades de representação, os responsáveis por atribuírem-se um papel fundamental na elaboração do projeto político nacional. $\mathrm{O}$ Estado também teve um papel determinante, cooptando os jornalistas e estimulando a concorrência entre os membros de profissões específicas para atuarem no projeto político nacional. $\mathrm{O}$ corporativismo proposto pelo Estado Novo, além de legitimar as competências especializadas, delegando funções públicas a membros de profissões específicas, traduziu-se ainda em redes institucionais, permitindo que as elites mais diversas, por meio de conselhos técnicos, entidades, associações e sindicatos, encontrassem uma maneira de atuar na esfera estatal. Assim, as associações profissionais tornavam-se recursos importantes para o investimento no Estado, contribuindo mais para fortalecer os contatos de determinados profissionais com o Estado do que para organizar e representar seus interesses no mercado de serviços.

Dessa forma, o Estado, além de estimular a organização profissional, investia amplamente em algumas delas. Foi o caso da ABI, que conquistou sua sede própria, nesse período, com os investimentos do governo. Contudo, para que a ABI adquirisse sua sede, fez-se necessário que todas as entidades de imprensa que existiam no Rio de Janeiro, naquele momento, unissem-se em torno de uma só entidade. Dessa união, saiu o presidente da ABI, Herbert Moses, que ficou na entidade de 1931 até 1966 . Nesse período, a entidade teve seu patrimônio enriquecido por meio das doações em dinheiro de Getúlio Vargas. Tal fato concedeu-lhe o título de Presidente de Honra da entidade e de sócio benemérito. Durante todo o Estado Novo, a $\mathrm{ABI}$ foi o centro de referência para políticos nacionais e internacionais, empresários, jornalistas e intelectuais, que a freqüentavam intensamente, constituindo-se como uma mediadora entre os interesses do governo e a defesa dos jornalistas. A ABI permaneceu, durante praticamente toda gestão de Herbert Moses, um espaço de aglutinação de políticos, letrados, intelectuais e jornalistas. A $\mathrm{ABI}$ abrigava um número expressivo de diplomatas, constituindo-se como um espaço importante de sociabilidade entre o jornalismo e a diplomacia. A gestão de Moses tornou-se o ponto culminante dessa prática de encontro de jornalistas e diplomatas. O próprio espaço da diplomacia, por abrigar muitos jornalistas e escritores, procurou uma intersecção com a ABI. Nesse espaço, conseguiu deixar penetrar o poder estatal, o que acarretou em desdobramentos muito variados, ocasionados pela presença de componentes do corpo diplomático nessa instituição. A ABI constituiu-se, dessa forma, em uma arena da política, em um espaço que tornava a consagração jornalística um recurso de visibilidade do Estado e para nele atuar durante o momento de organização da nação. Isso foi mais intenso durante todo o Estado Novo, mas o vínculo da $\mathrm{ABI}$ com a política perdurou por várias gestões.

A relação dos presidentes da casa com o universo da política governamental exemplifica o vínculo intenso entre a $\mathrm{ABI}$ e a política estatal. Ao longo dos seus 96 anos de existência, a entidade contou com presidentes jornalistas que exerciam, em sua maioria, além das atividades político-partidárias, também as literárias, circulando por espaços sociais diversos, além do jornalismo, como os da política e os da cultura; desempenhando funções não só em jornais, mas ocupando, ainda, cargos governamentais, na burocracia, atuando como senadores, governadores e deputados, e inserindo-se nas academias que visavam dar destaque àqueles que se dedicavam à produção literária. Os vínculos diversos dos presidentes da $\mathrm{ABI}$, indicam para uma combinação de diferentes tipos de recursos sociais, tais como recursos políticos, obtidos por meio da inserção em partidos e da ocupação de cargos políticos; recursos profissionais, possibilitados pela atuação em universidades, como professores, em jornais, como jornalistas e, ainda, aqueles obtidos pelo exercício de outras profissões, como a Medicina e o Direito. Os re- 
cursos obtidos nas mais diferentes esferas, como a da política, das profissões e da cultura, eram reconvertidos para a atuação na entidade, pois possibilitavam ocupar uma posição de destaque na mesma. Ao mesmo tempo em que os recursos acumulados pela atuação na entidade eram reconvertidos para a atuação em outros espaços sociais, como a política estatal.

\section{ENSINO SUPERIOR, FACULDADES DE JORNALISMO E FORMAÇÃO DO DIS- CURSO COMPETENTE}

As universidades também se desenvolveram como importantes espaços de atuação política. As primeiras faculdades de jornalismo, muitas delas criadas por empresas de comunicação e entidades que agregavam os profissionais de imprensa, apresentavam um projeto político amplo para a formação da nação e do Estado Nacional. Os cursos de formação superior representavam espaços importantes para lutar pela união nacional e pelo engrandecimento da nação: "para um Brasil cada vez maior e melhor". A primeira faculdade de jornalismo, criada em 1947, chamava-se Faculdade de Jornalismo Cásper Líbero, e era vinculada ao jornal A Gazeta. Anterior a essa data, outras tentativas de criação de cursos de jornalismo já haviam sido feitas pela ABI, que, durante o Primeiro Congresso Brasileiro de Jornalistas, em 1918, tentou criar a primeira escola de jornalismo, e pela Associação dos Profissionais de Imprensa de São Paulo que promoveu o Curso Livre de Jornalismo, no Brasil, no ano de 1943. O primeiro curso superior de jornalismo funcionou na Universidade do Distrito Federal, em 1935, valorizando a formação humanística do jornalista. Mas com a ditadura do Estado Novo, a Universidade do Distrito Federal foi extinta, e Vargas criou, em 1943, o curso de jornalismo da Faculdade Nacional de Filosofia, inaugurado somente em 1948. Os cursos de jornalismo surgidos, nesse período, pretendiam formar uma "elite cultural" capaz de contribuir para a construção da política brasileira, como mostra o relato abaixo, retirado do testamento de Cásper Líbero que, ao criar a faculdade de jornalismo, define os seguintes objetivos para o curso: "[...] objetivo patriótico, de iniciativas e campanhas por São Paulo, pelo Brasil, pela justiça, pelos nobres ideais, pela cultura e grandeza de nossa Pátria, servindo-se para isso de A Gazeta, do seu auditório, de seu Rádio e dos recursos do patrimônio que a doto; $b$ ) objetivo cultural, de cri- ar e manter uma escola de jornalismo e ensinamento de humanidades, particularmente português, prosa, estilo, literatura, eloqüência, história e filosofia, em cursos de grandes proporções, a começar pelo secundário e finalizar pelo superior; c) objetivo jornalístico, consistente em assegurar e desenvolver o nome, futuro, prosperidade econômica e prestígio de A Gazeta, mantendo-a órgão da genuína opinião pública e interesses da Pátria, aparelhada dos inventos e aperfeiçoamentos que o progresso for engendrando, fidelíssima da fundação" (HIME, 2005a, p. 14).

Tais objetivos implicavam na defesa de uma formação patriótica do jornalista, constituindo-se, assim, nos elos que aproximavam Cásper Líbero do nacionalismo do Estado Novo (HIME, 2005b). As escolas de jornalismo eram vistas como indispensáveis para uma formação cultural mais ampla e, sob esse aspecto, fundamentais para traçar os caminhos da nação. Os papéis das faculdades e dos cursos de comunicação eram o da realização da cultura e o da consolidação de um saber que permitisse impulsionar o progresso do país. Um exemplo dessa formação pode ser encontrado nos próprios currículos dos cursos de jornalismo, cujo centro era basicamente a formação humanística, composto por uma cultura geral, que incluía disciplinas como História do Brasil, Geografia do Brasil, História da Cultura Artística e Literária e matérias instrumentais, como Língua Portuguesa e História da Imprensa. Contudo, é somente a partir da década de 1970 que são incluídas disciplinas técnicas.

Como mostra Martins (1987), os cursos superiores, no Brasil, apareceram como uma das vias de ação desses agentes interessados em organizar o país, constituindo-se como um dos eixos de suas preocupações e colocando-os em relação direta com o Estado. A universidade e os cursos foram concebidos, desde o seu nascimento, mais como um instrumento de ação política do que um lugar de produção científica, de realização de pesquisa e de formação técnica. Nesse sentido, a universidade tinha como objetivo formar uma elite capaz de organizar e delinear os rumos do país.

As profissões e as instituições convergiam para o Estado possibilitando a articulação dos interesses por meio de conselhos técnicos, associações e sindicatos profissionais, universidades etc. Os representantes de profissões específicas, aos pou- 
cos, inseriram-se na construção orgânica da sociedade e do poder. A lei sindical, por exemplo, criou as condições para que o sindicalismo tornasse-se um instrumento político, por meio de direções sindicais. As associações profissionais voltavam-se para o Estado a fim de obterem apoio e recursos para atuar em nome de uma cultura nacional. Numa tentativa de cooptar certos atores membros de camadas profissionais, o governo oferecia-lhes a possibilidade de atuar politicamente, acenando com cargos burocráticos. No contexto dos anos 1925 e 1940, os atores membros de profissões específicas, como os jornalistas, os médicos, os advogados, mostravam-se preocupados, sobretudo, com o problema da identidade nacional e das instituições, colocando-se na condição de responsáveis pela construção e pela organização da nação (PÉCAUT, 1990).

Entretanto, os contextos seguintes, sobretudo após os anos 1970, representaram o momento em que a competência técnica e profissional representou um argumento importante na luta pela redemocratização do país e pela liberdade de imprensa e de expressão. Esse foi o momento da imposição do diploma de nível superior para o exercício do jornalismo, da criação de cursos de pós-graduação e de entidades que visavam reunir pesquisadores de jornalismo. Nesse momento, a formação universitária, em jornalismo, apareceu como indispensável para a constituição de uma ética profissional e para apreensão dos critérios técnicos da profissão. Nos anos mais difíceis da ditadura, principalmente após 1968, a ética, as normas e os objetivos profissionais foram defendidos, como uma forma de enfrentamento ao golpe militar. As camadas profissionalizadas conferiram-se um poder que na década de 1960 e 1970 apareceu associado ao conhecimento científico e especializado e, nesse sentido, o tema da profissionalização passou a ganhar destaque. Diferentemente do que aconteceu nas décadas anteriores, em que as camadas profissionais atribuíram-se um papel na elaboração da imagem da nação, nas décadas de 1960 e 1970, a reivindicação profissional associada à defesa das liberdades foi ressaltada (idem).

As estruturas institucionais, como a universidade e as faculdades, cujos investimentos cresceram nesse período, bem como a ideologia profissional e a recorrência ao "discurso competente", serviram ao mesmo tempo para legitimar posicionamentos em favor da liberdade de participação e da democracia, constituindo-se como uma maneira transfigurada de apoiar abertamente um discurso em defesa da livre expressão e manifestação. No contexto dos anos 1960 e 1970, uma grande parte dos jornalistas, sobretudo aqueles vinculados às entidades da categoria e à universidade, esteve presente nas lutas contra a censura e na constituição de uma frente de resistência contra o regime, alinhando-se às lutas políticas pelas liberdades democráticas como o Movimento pela Anistia dos Presos Políticos. Alguns exemplos podem ser citados, como as greves dos jornalistas e os congressos nacionais promovidos pelas entidades sindicais da categoria, que salientavam a defesa da liberdade de expressão e de imprensa, ao mesmo tempo em que reivindicavam uma regulamentação que valorizasse a formação profissional. Pode-se citar, ainda, a forte atuação dos jornais alternativos, bem como o empenho da Associação Brasileira de Imprensa, conhecida como a "casa dos jornalistas", em colocar-se à frente das campanhas contra a censura.

Nesse sentido, a competência especializada, a profissionalização e a filiação institucional tornaram-se recursos fundamentais para colocar em prática um conjunto de estratégias contra o autoritarismo militar. Em função disso, proliferouse um conjunto de associações que se encarregaram de defender a liberdade, a democracia, a sociedade civil organizada e, ao mesmo tempo, os interesses das categorias profissionais. Dentre essas entidades pode-se citar a Associação Brasileira de Imprensae a Ordem dos Advogados do Brasil (idem).

A formação profissional e o discurso da competência técnica tornaram-se trunfos importantes para agir contra o regime ditatorial. Em 1966, foi instalada a Escola de Comunicação e Artes da Universidade de São Paulo (USP), marcada por debates envolvendo a liberdade de imprensa, o ensino do jornalismo e da comunicação social e seu aspecto "técnico" e "prático". Os argumentos na defesa de disciplinas técnicas estavam relacionados à defesa do jornalismo como uma profissão específica, que exigia uma formação própria. A promoção de eventos científicos e acadêmicos representou um espaço importante de intervenção política, e a academia foi colocada a serviço de uma reivindicação pelas liberdades democráticas (VIANNA, 2005). 
A defesa da competência especializada, associada a uma estratégia de participação política, não aconteceu somente no jornalismo, mas manifestou-se em diversas áreas, como as Ciências Sociais e a Economia. No jornalismo, houve uma defesa generalizada, principalmente após 1968, da necessidade de adotar-se princípios de objetividade e neutralidade na construção das notícias. Ao mesmo tempo em que essa visão disseminou-se no jornalismo brasileiro, na conjuntura dos anos 1970, colocou em contraste dois modelos de definição de jornalismo. O primeiro constituía-se por aqueles que acreditavam na defesa de uma postura desengajada, necessária à prática do jornalismo "neutro" e "objetivo", em que a autonomia do profissional era sustentada pelo seu distanciamento de causas políticas, defendidas principalmente por jornalistas que ocupavam cargos e postos na "grande imprensa". O segundo, por aqueles que acreditavam na necessidade de um conhecimento específico, mas para elaborar informações com comentários críticos e, no qual, conseqüentemente, o jornal seria o porta-voz das demandas sociais, assumindo o papel de "formador de opiniões", posição essa defendida, sobretudo, pela imprensa alternativa e sindical, que despontava. Esse modelo acusava o anterior de despolitizar o jornalismo, escondendo e mascarando os posicionamentos ideológicos dos proprietários de meios de comunicação. Como mostra Silva (2004), para esse modelo, o jornalista era um trabalhador como outro qualquer, e não podia isolar-se no interior das redações, deixando de manifestar-se nos debates políticos. Seu papel implicava em uma intervenção direta na esfera política e na reivindicação de uma representatividade profissional.

Mas, apesar dos contrastes entre esses modelos, e das diferenças entre os jornalistas que aderiram a essas posturas, ambos constituíram um ato político de resistência diante da repressão e da censura. Os jornalistas voltados à "grande imprensa", ao defender a objetividade e o desengajamento, afirmavam que a cobertura baseava-se nos fatos e não em opiniões; com isso, pretendiam adquirir uma liberdade maior para compor suas matérias. A defesa do desengajamento passou a ser estratégica para as empresas jornalísticas conseguirem manter-se no período da ditadura. Do mesmo modo, aqueles que defendiam um engajamento na formação da opinião pública, politizando o jornalismo, e que estavam vinculados, sobretudo, aos sindicatos e jornais alternativos, criavam um es- paço de atuação em que tentavam combater a repressão do regime. Esses últimos, com o processo de abertura, no início da década de 1980 , passaram a aderir com mais intensidade aos partidos políticos de esquerda, como o Movimento Democrático Brasileiro (MDB), o Partido Comunista Brasileiro (PCB) e, posteriormente, o Partido dos Trabalhadores (PT). Os sindicatos dos jornalistas passaram a aderir a organismos intersindicais surgidos pelas oposições entre esses partidos de esquerda, como a Central Única dos Trabalhadores (CUT), que estava ligada ao Partido dos Trabalhadores. Nesse sentido, suas manifestações aparecem, cada vez mais, associadas à inserção em partidos políticos.

A temática da profissionalização, do conhecimento específico e da técnica jornalística atingiu vários setores do jornalismo. Os grandes jornais de circulação nacional (a Folha de S. Paulo e o Estado de S. Paulo) promoveram reformulações em sua estrutura interna e passaram a adotar outros procedimentos "especializados" e "objetivos", importados dos Estados Unidos, como os manuais de redação, que serviram como uma orientação técnica. Os manuais de redação, denominados stylebooks, fizeram parte das estratégias dos conglomerados jornalísticos nos Estados Unidos para vencerem a concorrência (RIBEIRO, 2003), mas, no Brasil, constituíram-se como uma das estratégias adotadas pelas empresas para vencer as limitações dadas aos jornais no momento do tolhimento da liberdade de imprensa e da ditadura militar. Dessa forma, o processo de profissionalização do jornalismo representa não somente uma forma de controlar o mercado e reservar os serviços aos especialistas, mas uma forma de atuar politicamente, seja em defesa da nação, da redemocratização, seja inserindo-se nas instâncias próprias da esfera da política, como os partidos políticos, os governos e a burocracia pública.

\section{CONCLUSÕES}

Uma das preocupações norteadoras deste texto consistiu em trazer contribuições pertinentes para a reflexão da formação das profissões em sociedades como a brasileira, em que a relação com a esfera da política torna-se fundamental. Tal reflexão é concernente, em primeiro lugar, aos limites das abordagens e dos modelos teóricos centrados no profissionalismo e no mercado de trabalho, e que, por sua vez, apresentam mais difi- 
culdades em lidar com a diversidade de experiências de profissionalização. Esses modelos ignoram experiências, como a brasileira, em que as profissões destacaram-se mais pela possibilidade de influenciar o Estado por meio do seu conhecimento especializado do que pela possibilidade de estabelecer um monopólio de mercado. Nessas condições, o projeto de profissionalização ocorre simultaneamente à construção do Estado Nacional e as diversas instituições profissionais (associações, sindicatos, universidades) exerceram tanto a função de controle do exercício do jornalismo quanto se constituíram em instâncias de acumulação de recursos sociais fundamentais para permitir um investimento na política estatal e em outras esferas sociais. Portanto, o Estado, nessas condições, não é um entrave, mas um recurso poderoso, por meio do qual as profissões exercem seu poder.

Em segundo lugar, esse texto traz elementos para a reflexão das fronteiras entre os espaços profissionais que, no caso do Brasil, apresentamse mais flexíveis e, desse modo, mais permeáveis a articulações com outros espaços sociais. Nessas situações, as profissões não se consolidaram apenas em torno de "ideologias meritocráticas" capazes de contribuir para sua autonomia, mas seu desenvolvimento implicou numa expansão das atividades profissionais e, desse modo, a definição de "profissão" remeteu não somente a um meritocratismo e a um acúmulo de recursos escolares, mas, também, ao acúmulo de recursos variados e ao exercício profissional em esferas sociais diversas. Nessa direção, o exame das relações entre Estado e profissões revela o alto grau de imbricação entre essas duas esferas e, inclusive, a importância que assumiu o Estado frente a um mercado de atuação profissional. O estabelecimento das fronteiras jurídicas profissionais representou não apenas a necessidade de definir e regular o espaço profissional, estabelecendo uma reserva de mercado, mas, fundamentalmente, caracterizou-se pela utilização da profissionalização como um recurso para agir na esfera da política partidária e governamental. Com base nisso, é possível afirmar que o reconhecimento profissional, por meio da ação das entidades de representação e da universidade, tornava-se um importante recurso para a atuação na política brasileira.

Contudo, essa não é uma peculiaridade do jornalismo. Outros trabalhos mostram que esse processo também aconteceu no Direito, por meio de instituições como a Ordem dos Advogados, em que os bacharéis colocaram-se na condição de influenciar o Estado por meio do conhecimento jurídico (BONELLI, 1999). O mesmo aconteceu na Medicina, em que o Estado tornou-se o agenciador dos serviços de saúde pública, expandindo as possibilidades de atuação profissional. Nesse processo de expansão dos serviços de saúde, as entidades, como a Academia Nacional de Medicina, lutaram para garantir aos médicos espaços de decisão na estrutura burocrática (CORADINI, 1997a; 2005, PEREIRA NETO, 2001). Assim, as profissões, no Brasil, surgem associadas aos interesses do Estado, gerando a possibilidade de influenciá-lo por meio do conhecimento especializado. Em diferentes épocas, como no Estado Novo de Vargas e no Estado autoritário dos militares, a relação entre Estado e profissões era intensa, uma vez que o próprio Estado apropriou-se das propostas dos profissionais cooptando-os, além do fato de os próprios profissionais também estarem prontos a colocar seus conhecimentos a serviço dos interesses nacionais (PÉCAUT, 1990). Portanto, o acesso ao Estado e à esfera política, de modo geral, confere o acesso a uma das esferas fundamentais no acúmulo de recursos e de carreiras bem sucedidas.

Fernanda Rios Petrarca (f.petrarca@uol.com.br) é Doutora em Sociologia pela Universidade Federal do Rio Grande do Sul (UFRGS) e Professora da Universidade Federal do Sergipe (UFS).

\section{REFERÊNCIAS BIBLIOGRÁFICAS}

BARBOSA, M. L. O. 1993. A Sociologia das Profissões : em torno da legitimidade de um objeto. Boletim Informativo e Bibliográfico de Ciências Sociais, Rio de Janeiro, n. 35, p. 330 .
BARICKMAN, B. J. \& LOVE, J. L. 2006. Elites regionais. In : HEINZ, F. (org.). Por outra história das elites. Rio de Janeiro : FGV. 
BOIGEOL, A. \& DEZALAY, I. 1997. De l'agent d'affaires au barreau : conseils jurudiques et la construction d'un espace professionnel. Genèses, n. 27, p. 49-68, juin. Disponível em : http://www.persee.fr/web/revues/home/ prescript/article/genes_11553219_1997_num_27_1_1447. Acesso em : 21.dez. 2009 .

BOLTANSKI, L. 1973. L'espace positionnel. Multiplicité des positions institucionnelles et habitus de classe. Revue Francaise Sociologique, Paris, v. 14, n. 14-1, p. 3-26. Disponível em : http://www.persee.fr/web/ revues/home/prescript/article/rfsoc_00352969_1973_num_14_1_2176. Acesso em : 21.dez.2009.

BONELLI, M. G. 1999. O Instituto da Ordem dos Advogados Brasileiros e o Estado : a profissionalização no Brasil e os limites dos modelos centrados no mercado. Revista Brasileira de Ciências Sociais, São Paulo, v. 14, n. 39, p. 61-81, fev. Disponível em : http:// www.scielo.br/pdf/rbcsoc/v14n39/1722.pdf. Acesso em : 21.dez.2009.

BOURDIEU, P. 1984. Homo academicus. Paris : Editions de Minuit.

COELHO, E. C. 1999. As profissões imperiais. Medicina, Engenharia e Advocacia no Rio de Janeiro 1822-1930. Rio de Janeiro : Record.

CONNIFF, M. L. 2006. A elite nacional. In : HEINZ, F. (org.). Por outra história das elites. Rio de Janeiro : FGV.

CORADINI, O. L. 1997a. Grandes famílias e "elite profissional" na Medicina no Brasil. História, Ciências, Saúde, Rio de Janeiro, v. 3, n. 3, p. 425-466. Disponível em : http:// www.scielo.br/pdf/hcsm/v3n3/v3n3a04.pdf. Acesso em : 21.dez.2009.

1997b. Origens sociais e princípios de hierarquização escolar : a formação de "intelectuais à brasileira". Cadernos de Ciência Política, Porto Alegre, n. 6, p. 1-55.

2005. A formação da elite médica, a Academia Nacional de Medicina e a França como centro de importação. Estudos Históricos, Rio de Janeiro, n. 35, pp. 3-22. Disponível em : http://virtualbib.fgv.br/ojs/index.php/reh/ article/viewArticle/2232. Acesso em : 21.dez.2009.
DEZALAY, I. \& GARTH, B. 2002. Recycler lês hommes d'État pour restructurer l'État : des héritiers de la culture juridique européenne aux technopols made in USA. In : . $L a$ Mondia-lisation des Guerres de Palais. Paris : Éditions du Seuil.

DUBAR, C. \& TRIPIER, P. 1998. Sociologie des Professions. Paris : Armand Colin.

FREIDSON，E. 1998. Renascimento do profissionalismo. São Paulo : EDUSP.

2001. La Teoria de Las Profesiones. Estado Del Arte. Perfiles Educativos, Ciudad del Mexico, v. 23, n. 93, p. 28-43. Disponível em : http://redalyc.uaemex.mx/redalyc/pdf/ 132/13209303.pdf. Acesso em : 21.dez.2009.

HIME, G. V. C. 2005a. Construindo a profissão de jornalista : Cásper Líbero e a criação da primeira escola de jornalismo do Brasil. In : CONGRESSO BRASILEIRO DE CIÊNCIAS DA COMUNICAÇÃO, 28., Universidade Estadual do Rio de Janeiro, 5-9.set. Anais... Rio de Janeiro : Intercom.

2005b. Cásper Líbero entre o profissional e o mito : inventário crítico das fontes bibliográficas e hemerográficas. In : ENCONTRO NACIONAL DA REDE ALFREDO DE CARVALHO, 3., Novo Hamburgo. Anais... Novo Hamburgo : Rede Alcar.

HUGHES, E. 1981. Men and Their Work. Wesport, CT. : Greenwood.

LOUREIRO, M. R. 1997. Os economistas no governo. Rio de Janeiro : FGV.

MARANHÃO FILHO, L. 1995. Legislação e comunicação : direito de comunicação. São Pau-lo : LTr.

MARTINS, L. 1987. A gênese de uma intelligentsia : os intelectuais e a política no Brasil, 1920-1940. Revista Brasileira de Ciências Sociais, São Paulo, v. 2, n. 4, p. 1-26. Disponível em : http://www.anpocs.org.br/ portal/publicacoes/rbcs_00_04/ rbcs04_06.htm. Acesso em : 21.dez.2009.

NEVEU, E. 2001. Sociologie du jornalisme. Paris : La Decouverte.

PARSONS, T. 1977. Las profesiones liberales. In : SILLS, D. L. (org.). Enciclopedia Internacional de las Ciencias Sociales. Madrid : Aguilar. 
PÉCAUT, D. 1990. Os intelectuais e a política no Brasil. Entre o povo e a nação. São Paulo : Ática.

PEREIRA NETO, A. 2001. Ser médico no Brasil. O Presente no Passado. Rio de Janeiro : FIOCRUZ.

PETRARCA, F. R. 2007. O jornalismo como profissão : recursos sociais, titulação acadêmica e inserção profissional dos jornalistas no Rio Grande do Sul. Porto Alegre. Tese (Doutorado em Sociologia). Universidade Federal do Rio Grande do Sul. Disponível em : http:// hdl.handle.net/10183/10761. Acesso em : 21.dez. 2009

RIBEIRO, L. M. 2003. A imprensa e a esfera pública : o processo de institucionalização do jornalismo no Brasil (1808-1964). In : ENCONTRO NACIONAL DA REDE ALFREDO DE CARVALHO, 1., Rio de Janeiro, 1-5.jun. Anais... Rio de Janeiro : Rede Alcar. Disponível em : http://www.revistas.univerciencia.org/
index.php/cs_umesp/article/viewFile/166/124. Acesso em : 21.dez.2009.

RODRIGUES, M. L. 2002. Sociologia das Profissões. Portugal, Celta.

SILVA, M. A. R. 2004. Jornalistas : o sindicato no dilema entre a militância e o profissionalismo. Revista $P J: B r$, São Paulo, n. 3, p. 1-29. Disponível em : http:// www.eca.usp.br/pjbr/arquivos/ monografia3_f.htm. Acesso em : 21.dez.2009.

VELLOSO, M. P. 1982. Uma configuração do campo intelectual. In : OLIVEIRA, L. L. (org.). Estado Novo : ideologia e poder. Rio de Janeiro : J. Zahar.

VIANNA, R. P. A. 2005. Pra não dizer que não falei das flores : a modernidade do projeto pedagógico fundador do curso de jornalismo da ECA e seu impacto nacional. In : ENCONTRO NACIONAL DA REDE ALFREDO DE CARVALHO, 3., Novo Hamburgo. Anais... Novo Hamburgo : Rede Alcar. 
CONSTRUCTION OF THE STATE, THE POLITICAL SPHERE AND THE PROFESSIONALIZATION OF JOURNALISM IN BRAZIL

\section{Fernanda Rios Petrarca}

This article analyzes the relationship between processes of State construction and proposals for the organization of professional groups in Brazil, taking the case of journalism and its professionalization as our empirical reference. We consider the relationship between a series of phenomena - the emergence of formal criteria for exercise of the profession, the creation of representative entities and the establishment of institutions for professional training - and the social uses of this process with the trajectories of the agents who participate. One of the major goals of our text is to supply elements, based on particular theoretical and methodological conceptions, to reflect on the process of organization and institutionalization of the professions in Brazil and their broader relation to the political sphere. Within the Brazilian context, we have seen that the dynamics for construction of political and professional spheres occur simultaneously and with heavy mutual interference. Thus, through the experience of journalism, we are able to demonstrate that professional recognition becomes a resource of action in Brazilian politics.

KEYWORDS: State; professions; journalism; political sphere. 

JOURNALISME AU BRÉSIL

\section{Fernanda Rios Petrarca}

Cet article analyse la relation entre le processus de construction de l'état et le projet proposé pour l'organisation des mondes profissionnels au Brésil, en ayant comme référence empirique le cas du journalisme et sa professionnalisation. On a pris en compte la relation entre l'introduction des critères formels d'entrée dans l'activité professionnelle, la création d'organismes représentant la catégorie professionnelle et la mise en oeuvre des institutions d'enseignement avec les usages sociaux de ce processus et les trajectoires des agents impliqués. L'un des principaux objectifs de ce texte consiste à fournir des éléments, base sur certains concepts théoriques et méthodologiques, qui puissent mener à la réflexion du processus d'organisation et d'institutionnalisation des professions au Brésil et son rapport au politique en général. Dans le contexte brésilien, on a observé que la dynamique de la construction d'une sphère politique et professionnelle se produit simultanément avec une forte interférence entre elles. Donc, de l'expérience du journalisme il est demontré que la reconnaissance professionnelle est devenue une ressource pour l'action dans la politique brésilienne.

MOTS-CLÉS : État ; profession ; journalisme ; politique. 